Accepted Manuscript - Women's Health Issues

\title{
I-DECIDE: An online intervention drawing on the Psychosocial Readiness Model for women experiencing domestic violence
}

\author{
Laura Tarzia', Elizabeth Murray², Cathy Humphreys', Nancy Glass ${ }^{3}$, Angela Taft ${ }^{4}$, Jodie \\ Valpied' and Kelsey Hegarty' \\ ${ }^{1}$ The University of Melbourne, Victoria, Australia \\ ${ }^{2}$ University College, London, UK \\ ${ }^{3}$ Johns Hopkins University, Maryland, USA \\ ${ }^{4}$ La Trobe University, Victoria, Australia
}

\begin{abstract}
Background: Domestic violence (DV) perpetrated by men against women is a pervasive global problem with significant physical and emotional consequences. While some face-to-face interventions in health care settings have shown promise, there are barriers to disclosure to health practitioners and women may not be ready to access or accept help, reducing uptake. Similar to the mental health field, interventions from clinical practice can be adapted to be delivered by technology.

Purpose: This paper outlines the theoretical and conceptual development of I-DECIDE, an online healthy relationship tool and safety decision aid for women experiencing DV. The paper explores the use of the Psychosocial Readiness Model as a theoretical framework for the intervention and evaluation.

Methods: This is a theoretical paper drawing on current theory and literature around health care and online interventions for DV.

Results: The paper argues that the internet as a method of intervention delivery for DV might overcome many of the barriers present in health care settings. Using the Psychosocial Readiness Model as a framework for an online DV intervention may help women on a pathway to safety and well-being for themselves and their children. This hypothesis will be tested in a randomised controlled trial in 2015/6.

Conclusion: This paper highlights the importance of using a theoretical model in intervention development and evaluation.
\end{abstract}

Key Words: domestic violence; intervention; online; women; theoretical development; Psychosocial readiness

\section{Introduction}

Domestic violence (DV) is defined as any physical, sexual, psychological or economic violence that occurs between former or current spouses or partners (Council of Europe, 2011). It is a common social problem worldwide, and one that is distinctly gendered (Ellsberg \& Heise, 2005; World Health Organisation, 2013). Although it is true that lifetime prevalence of isolated violent acts within relationships is comparable between genders, repeated, coercive, sexual or severe physical violence is largely perpetrated by men against women (World Health Organization, 2013). Women experience more frequent and severe DV, are more likely to sustain serious injury and fear for their lives than men (Taft, Hegarty, \& Flood, 2001).

The prevalence of DV is particularly alarming in light of its association with a range of negative health outcomes for women and children (World Health Organization, 2013). Research consistently shows that abused women are at increased risk of depression, anxiety, post-traumatic stress disorder (PTSD) and suicide (Rees et al., 2011), as well as physical 
problems (Ellsberg, Jansen, Heise, Watts, \& Garcia-Moreno, 2008). Children of these women also experience negative health and developmental effects, whether as targets of violent behaviour or witnesses to it (Bedi \& Goddard, 2007).

Despite these negative outcomes, there is limited evidence of effectiveness for interventions in health care settings, with inconclusive results in terms of the effects on women's physical and psychosocial wellbeing (Bair-Merritt et al., 2014; Feder et al., 2009; Ramsay et al., 2009; Ramsay, Feder, \& Rivas, 2006; Taft et al., 2013). There are barriers within health care settings that may prevent effective response. Many women are uncomfortable with revealing that they are experiencing DV, even if the issue is raised in a sensitive manner by the health professional (O'Doherty, Taft, McNair, \& Hegarty, In Press). They may feel that the abuse is not serious enough to mention (Hegarty \& Taft, 2001), or worry about disclosure if their abusive partner sees the same health care professional (Hegarty \& Taft, 2001). The pathway to disclosure can be long and challenging for women, and by the time the health professional becomes aware of the abuse, if at all, they may have missed a valuable opportunity to intervene earlier and more effectively (Reisenhofer \& Taft, 2013).

Offering a DV intervention in an online format may assist in overcoming some of the barriers encountered in health care settings. Online interventions are being increasingly used as a way of self-managing health conditions, with promising results (Murray, Burns, See Tai, Lai, \& Nazareth, 2005). Lintvedt et al. (2013) point out that an internet-based intervention is constantly available and accessible from any location. This allows women to access the intervention at unexpected times when an abusive partner is not present, as opposed to the health care setting where they must schedule an appointment. Delivering an intervention online also allows women to self-identify and self-manage without disclosure to a third party. This may be particularly beneficial for women who are unable or unwilling to disclose the abuse to a health care professional and would not attend a specialised support service because they do not perceive themselves as a 'domestic violence victim' (Zink, Elder, Jacobson, \& Klostermann, 2004). An online format may also facilitate equity of access for groups of women who might otherwise be disadvantaged such as: women in remote or rural locations, women with disabilities, or women who are closely monitored by an abusive partner. In Australia, currently over $80 \%$ of households have access to the internet (Australian Bureau of Statistics, 2014) and in the US it is over 75\% of households (File \& Ryan, 2014). Women who do not have safe internet access often have access in other locations such as family or friends' homes, public libraries or community agencies (Australian Bureau of Statistics, 2014). Minority groups and lower income-earners often access the internet wirelessly using a smartphone (Zickuhr \& Smith, 2012).

In a recent systematic review of online health interventions, Webb et al. (2010) examined the role of theoretical background, behaviour change techniques, and mode of delivery on the intervention's effectiveness. They found that increased use of theory to inform the intervention led to a larger effect size. In terms of behaviour change techniques, the most valuable were found to be information provision, self-monitoring, and problem solving, with action planning and the provision of feedback also having significant positive effects. Interventions that provided an 'enriched information environment' and offered automated tailored feedback were found to have significant effects on behaviour change.

This paper will describe I-DECIDE, an online healthy relationship tool and safety decision aid for women experiencing DV in Australia developed by the authors and adapted from the IRIS online decision aid (Glass, Eden, Bloom, \& Perrin, 2010). The paper explores the theoretical and conceptual development of this innovative online intervention rather than reporting on data or findings. The paper will firstly outline existing work - both online and clinical - that the I-DECIDE intervention builds on. It then explores the Psychosocial 
Readiness Model as a theoretical framework for DV interventions (Chang et al., 2010; Cluss et al., 2006), and explains the causal pathway for how I-DECIDE operationalises this theory in practice.

\section{Previous Work Informing I-DECIDE}

Interventions for domestic violence

I-DECIDE is informed by pilot work on an online DV intervention conducted in the US by Glass and colleagues (the IRIS Project) (Glass et al., 2010). To our knowledge, IRIS is the first such intervention developed to date, with similar interventions being developed in New Zealand (Koziol-McLain et al., 2015) and Canada (NCT02258841). Drawing on the theoretical framework of empowerment (Dutton, 1992), the US intervention focuses on reducing decisional conflict, while also increasing safety behaviours. Dutton's empowerment model focuses on increasing women's safety and enhancing choice-making and problemsolving, and is a commonly-used model for DV interventions. The IRIS intervention takes the form of a website designed to help women identify and decide on the relative importance of a range of possible competing priorities, and having done this, develop an appropriate safety plan. In a preliminary study, Glass et al (2010) found that after a single use, women felt more supported in their decisions $(p=0.012)$ and had less total decisional conflict $(p=$ 0.014). Most of the participants in the preliminary study, however, had already left an unsafe relationship, and the results of a larger trial that includes women who are still being abused have yet to be determined.

I-DECIDE also builds on the weave project (Hegarty, O'Doherty, Gunn, Pierce, \& Taft, 2008), a randomised controlled trial that evaluated the effectiveness of a face-to-face counselling intervention in the primary care setting for women experiencing fear of a partner (Hegarty et al., 2013b). The doctors in the intervention group were provided with training in the delivery of a counselling intervention involving woman-centred care, active listening, motivational interviewing techniques and non-directive problem solving to validate and respond to the woman's experiences and feelings (Hegarty et al., 2013b). The I-DECIDE intervention aims to translate aspects of the weave counselling intervention - tailored responses and messaging and the use of motivational interviewing and non-directive problem solving tools - into an online format. It can thus be seen as a form of therapeutic intervention, which differentiates I-DECIDE from the other similar websites being developed in the USA, Canada and New Zealand, which are primarily decision aids.

The counselling intervention in weave was based on the Psychosocial Readiness Model, which is described in more detail in the next section. The intervention was designed to increase women's awareness of the abuse, her sense of perceived support through being listened to and validated by the doctor, and her self-efficacy through safety planning and nondirective problem solving. The results showed that women who received the invitation for counselling felt more supported by the doctor, had more safety discussions with the doctor, felt more self-efficacious and were less depressed (Valpied, Cini, O'Doherty, Taket, \& Hegarty, 2014). The intervention was generally received positively by the women who participated, although uptake was low (around 50\% of intervention group). Reasons for not going to see the doctor for counselling included the women not being ready or not perceiving a need for counselling, or because they were already seeking help elsewhere (Hegarty et al., 2013b).

\section{The Psychosocial Readiness Model}

Recently, the importance of tailoring health care and service responses to DV according to the individual woman has been highlighted (Reisenhofer \& Taft, 2013; Zink et al., 2004). Understanding a woman's readiness for action may increase the effectiveness of support. It 
may also help prevent inappropriate health care responses such as encouraging a woman to 'just leave', when this may result in increased stress, subject her to retaliatory violence from the partner, or other negative outcomes (Campbell, Webster, \& Koziol-McLain, 2003).

A range of models have been used to understand women's readiness for action, with the most widely-used being the Transtheoretical Model of Change (TTM) or the Stages of Change Model (Prochaska \& DiClemente, 1982). The TTM has been applied in other behaviour change contexts such as smoking cessation, but various theorists have advocated its application in addressing DV (Haggerty \& Goodman, 2003; Reisenhofer \& Taft, 2013). In this context, women are categorised into one of five 'stages': precontemplative, contemplative, preparation, action, or maintenance, which describe her journey from awareness of the abuse through to taking action for change and maintaining it over the long term (Reisenhofer \& Taft, 2013).

There is certainly merit to the idea that a woman's readiness for action should be taken into account when seeking to develop or implement an effective DV intervention. The TTM, however, has been challenged on the grounds that the target for change is unclear, because the woman has no control over the partner's abusive behaviour or other external factors (Hegarty et al., 2008) . Further, the readiness of the intervention system to support women's decision-making and change processes may be under-estimated and underdeveloped (Humphreys \& Thiara, 2011). Stage-based theories have also been questioned for their lack of appropriateness to complex behaviours such as DV (Cluss et al., 2006), since women may be in multiple stages simultaneously.

The Psychosocial Readiness Model (PRM) (Cluss et al., 2006) was developed as an alternative model to the TTM, based on indepth qualitative work with women survivors. In this model, readiness is described as a continuum with a balance of internal and external factors determining how the woman moves from maintaining the status quo through to a desire for action or change (Cluss et al., 2006). Rather than categorising women into a particular 'stage', the PRM takes into account the fluid and changeable nature of women's actions and desires. Women may be "moving ahead with [one] relevant action while moving away from readiness in another domain” (Cluss et al., 2006, p. 269). They may also define different things as 'actions', including health-seeking behaviours that do not have an end goal of leaving the abuser.

This model posits that there are three internal factors which can exert influence on readiness to change. Awareness is the woman's recognition that what she is experiencing is abuse. Self-efficacy is the woman's belief that she is able to achieve difficult tasks, or cope with adversity, a belief which is often eroded by emotional abuse from a partner (Benight \& Bandura, 2004). Perceived support describes the woman's sense that she is supported by those in her environment. It may not reflect the level of actual support that is available. The strength of all these variables affects the likelihood of movement along the change continuum. If one internal variable is strong, but the other two are weak, this may result in a lower motivation toward change. For example, as Cluss et al. (2006) describe, a woman may feel that she is supported by friends and family members, but remain unaware that her relationship is abusive.

In addition to the three internal factors, Cluss et al. (2006) acknowledge the impact that external factors - either positive or negative - can have on the change continuum. These can include unsupportive comments by family, friends, or health practitioners, and situational factors such as gaining or losing employment, or having access to an independent source of income. Figure 1 shows the way that these external factors can act on the internal factors to either reinforce, or obstruct, the woman's movement along the continuum. Qualitative work by Evans and Feder (2015) and Chang (2010) supports the use of the PRM in understanding 
the complexity of women's experiences when seeking a pathway to safety and making positive changes.

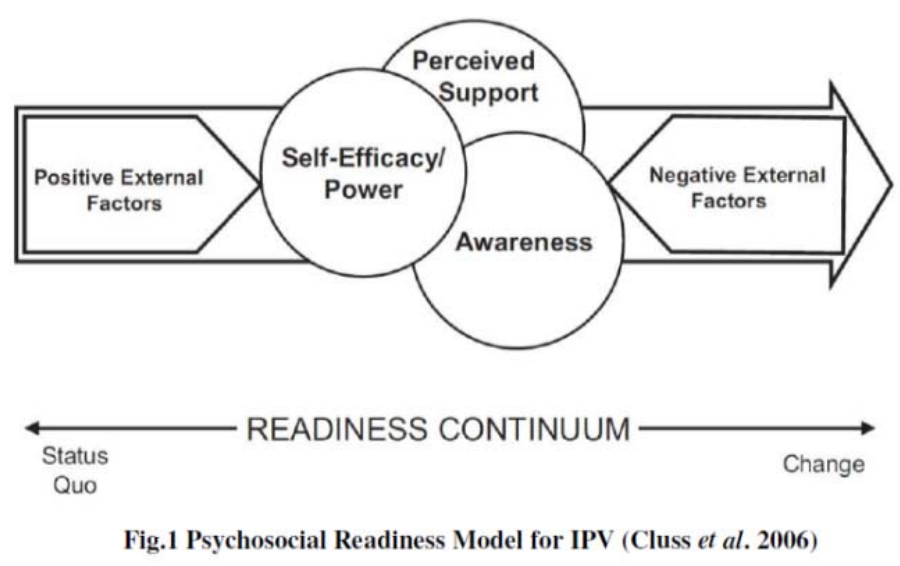

\section{Causal Pathway for the I-DECIDE intervention}

It can be difficult to determine what outcomes a DV intervention should target, whatever the mode of delivery (Hegarty et al., 2008; O'Doherty et al., 2014). A goal of reducing exposure to violence may be unrealistic for a brief intervention in the short-term. Moreover, Chang et al. (2010) have demonstrated that leaving the abusive partner may also be an unreliable measure of an intervention's success, since women may leave only to return again after a period of time. O’Doherty et al. (2014) have comprehensively reviewed potential outcomes of DV intervention trials and made a number of recommendations, including development of a causal pathway and exploration of any intermediate variables that may influence outcomes.

In the case of I-DECIDE, the PRM provides the framework for the potential outcomes of the intervention. The three internal factors identified by the model - awareness, selfefficacy and perceived support - have already been shown in qualitative work to be closely associated with positive change in women who have experienced DV (Chang et al., 2010; Cluss et al., 2006; Evans \& Feder, 2015). In order for interventions to act on the three key PRM elements, Cluss et al. (2006) have stated that they should:

...provid[e] information about [DV] and healthy/unhealthy relationships to raise awareness; assist[] in the identification of positive support persons; and engag[e] in collaborative problem solving with women to support self-efficacy... (p.272).

This has been carefully considered in the development of I-DECIDE, as shown in the below causal pathway model (Figure 2). 


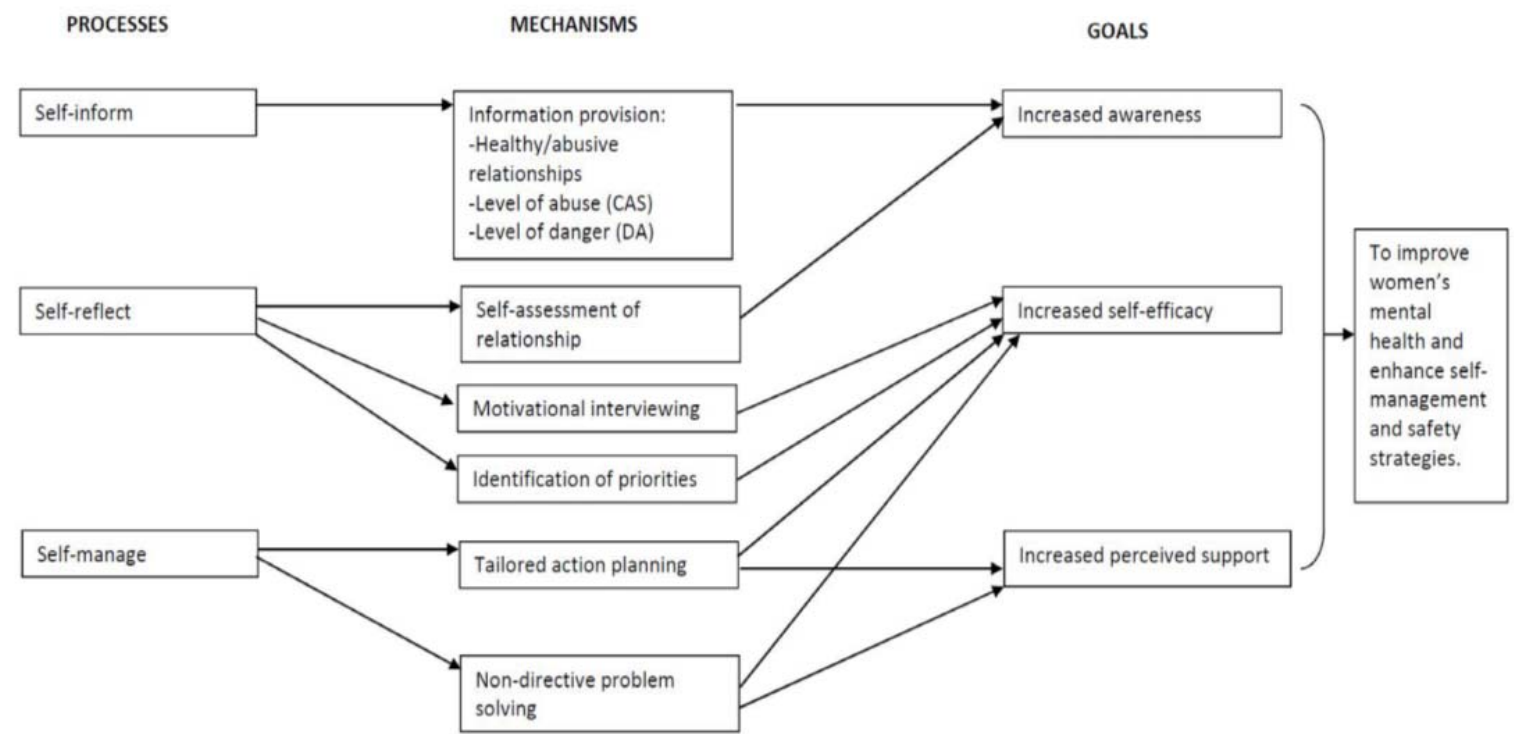

Fig. 2 I-DECIDE causal pathways

In addition to acting on awareness, perceived support and self-efficacy, it is proposed that I-DECIDE may also have a positive impact on women's mental health. Existing mental health research in a variety of contexts (Maciejewski, Prigerson, \& Mazure, 2000; Sawatzky et al., 2012) strongly supports the mediating effects of self-efficacy on mental health, specifically depression. Furthermore, the use of computers and other interactive technologies to deliver interventions for depression has also shown positive results (Christensen, Griffiths, \& Jorm, 2004; Lintvedt et al., 2013; Richards \& Richardson, 2012). It is therefore hypothesised that by acting on abused women's self-efficacy, I-DECIDE might also reduce their depressive symptoms. Below we describe in more detail the I-DECIDE intervention, and how its specific elements may achieve these outcomes.

\section{I-DECIDE: An online healthy relationship tool and safety decision aid for women experiencing domestic violence}

The I-DECIDE intervention will be evaluated through a randomised controlled trial in 20152016, comparing its effectiveness to a comparison website that represents minimum safe practice (basic resources and a generic emergency safety plan). The I-DECIDE trial is described in detail elsewhere, including recruitment and screening protocols (Accepted 20/7/15). In brief: women aged between 16 and 50 who respond to advertisements on popular websites and social media asking if they feel unsafe in their relationship will be directed to the I-DECIDE study homepage (see figure 3). 


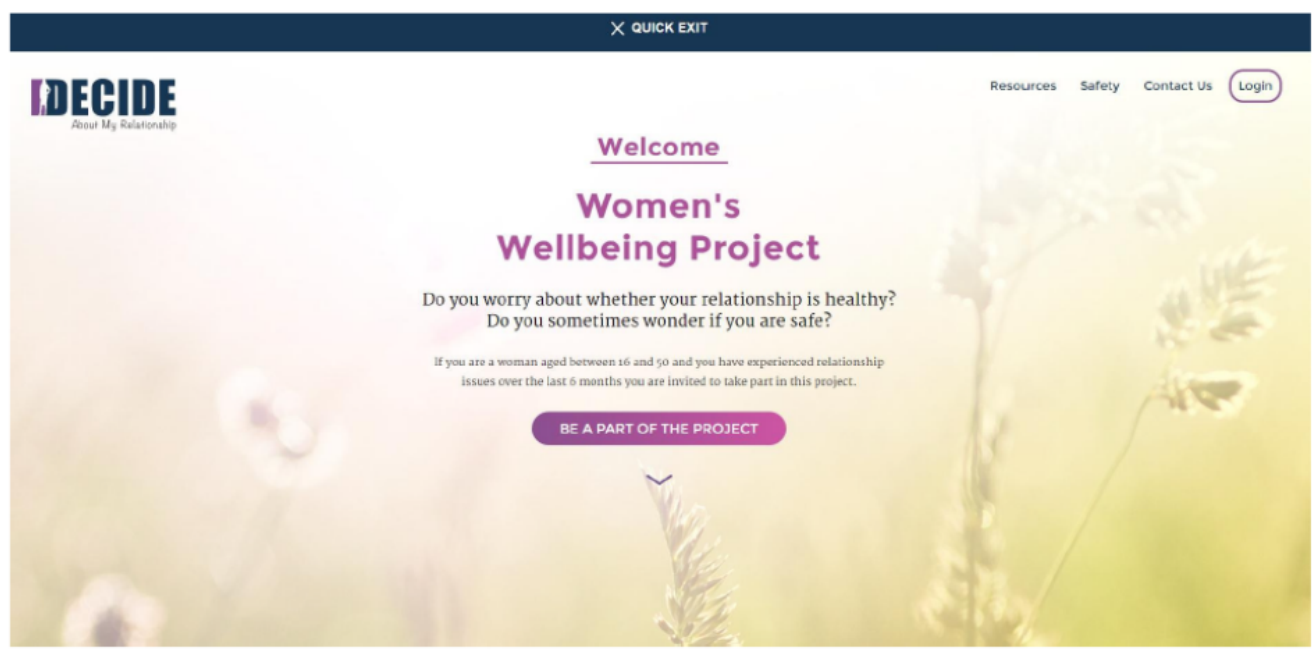

Figure 3-I-DECIDE homepage

I-DECIDE can be accessed on computers, tablets or smart phones. When women attempt to sign up they will complete a short screening survey to determine their eligibility (including whether they have experienced physical, sexual, or emotional abuse or fear of an (ex) partner in the past six months). If they are eligible, they are automatically emailed a secure username and password to proceed. The upper age limit has been set at 50 for the trial due to the fact that women of child-bearing age bear the greatest health burden associated with DV, and are the most likely to be in relationships where DV is present. Once the trial is completed, the website will be available to women of all ages. An outline of the intervention structure is displayed in Fig 4.

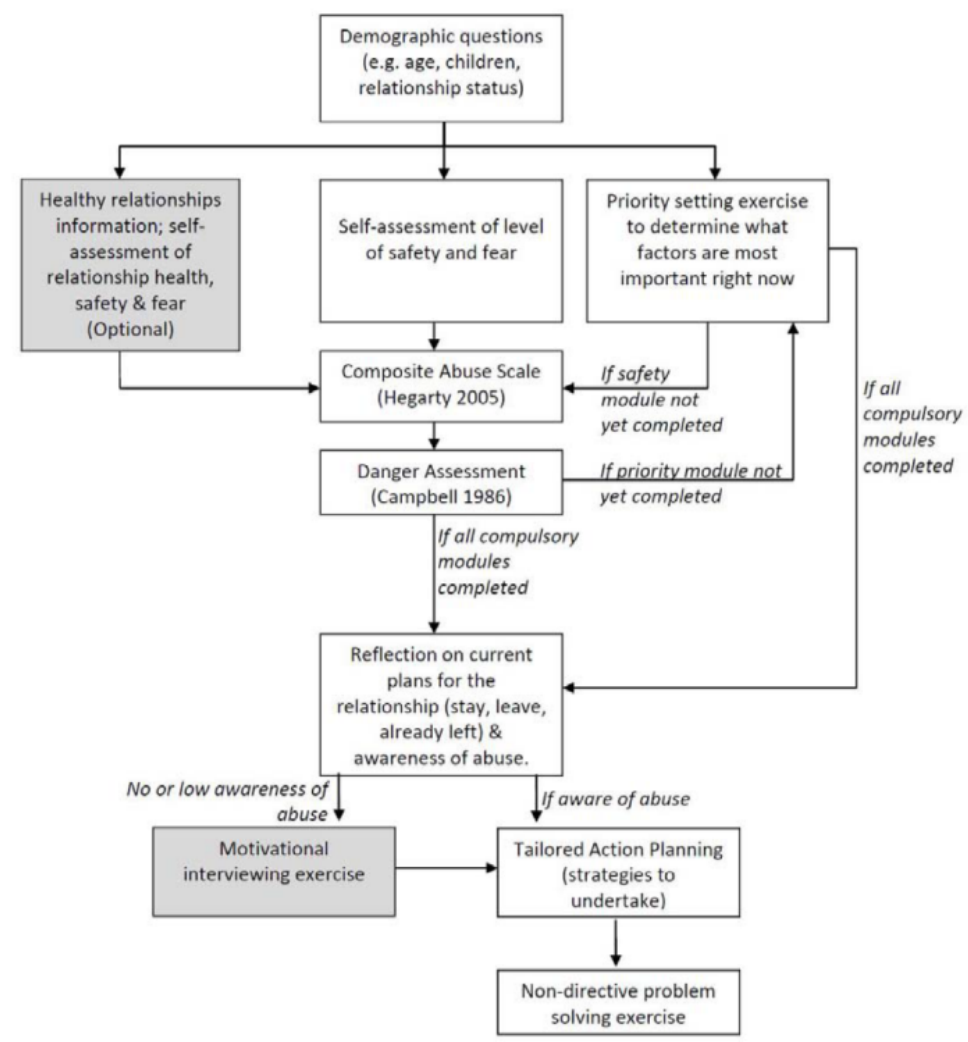

Fig.4 I-DECIDE structure 
When women log in to I-DECIDE, they will be asked to provide some basic biographical information such as their age, relationship status, and whether they have children. They will then be given a choice of three modules that focus on different areas: healthy relationships, safety, and priorities. While women may choose which of the modules they wish to begin with, the safety module and the priorities module are compulsory. The three modules are designed to address the needs of women who are in different places on the action continuum. For example, the healthy relationship tool is targeted at women who may not be ready to acknowledge that their relationship is abusive, but who want more information. To increase their level of awareness, the module will outline features of a healthy relationship, and will give women the opportunity to assess how they think their own relationship compares.

The second module is primarily targeted at women who are aware that their relationship is unhealthy, but who may be uncertain about their level of safety. The module will direct women to complete two validated tools: the Composite Abuse Scale (CAS) (Hegarty, Bush, \& Sheehan, 2005), and the Danger Assessment (Campbell, 1986). The Composite Abuse Scale (Hegarty et al., 2005) will assess whether women are experiencing emotional abuse and/or harassment, physical abuse, both emotional and physical abuse, or severe combined abuse. The Danger Assessment (Campbell, 1986) will determine women's level of risk for homicide based on a number of factors such as a partner's gun ownership or possessive behaviours. It also has an interactive calendar component that will allow women to drag and drop events into a calendar to determine whether the violence is escalating. Again, completion of the tools will allow women to self-reflect and is likely to raise awareness. Some women may still find it difficult to accept and name the level of abuse they are experiencing despite the results of the assessment being given to them. Messaging will be provided that is tailored and responsive to a woman's level of abuse and danger (see Table 1 below). The messages were developed in consultation with women so that, as much as possible, it might be able to emulate the empathetic and supportive response of a trained counsellor.

\section{Table 1. Examples of messaging}

\begin{tabular}{|l|l|}
\hline \multicolumn{1}{|c|}{ Category } & \multicolumn{1}{c|}{ Message } \\
\hline $\begin{array}{l}\text { Composite Abuse Scale - } \\
\text { Severe Combined Abuse }\end{array}$ & $\begin{array}{l}\text { You seem to have experienced serious abusive behaviours } \\
\text { from your partner. It is not acceptable for these things to } \\
\text { happen in relationships. It is probably affecting your mental } \\
\text { and physical health. A bit later, this website will suggest some } \\
\text { things you could try to help you look after yourself during this } \\
\text { stressful time. }\end{array}$ \\
\hline $\begin{array}{l}\text { Danger Assessment - Variable } \\
\text { Risk (lowest level) }\end{array}$ & $\begin{array}{l}\text { In an unhealthy relationship, things can sometimes change } \\
\text { quickly for the worse. It is a good idea to regularly assess how } \\
\text { the relationship is going, and if you start to feel afraid or } \\
\text { unsafe, talk to someone like a friend, family member, or } \\
\text { Relationships Australia (confidentially) on 1300 364 277. } \\
\text { Remember, if the violence is escalating, or in an emergency, } \\
\text { call 000. Relationship issues can be stressful, so a bit later this } \\
\text { website will suggest some things you could try to help you } \\
\text { take care of yourself. }\end{array}$ \\
\hline
\end{tabular}

The third module will provide women with the opportunity to weigh up different priorities in a graphical format that facilitates consistency (Eden et al., 2009). The priorities are: safety, health and wellbeing, having resources, feelings for partner, and children's safety and wellbeing (if applicable). Priorities were initially determined by Glass and colleagues in 
the US through reviewing the literature on women's responses to violence (Glass et al., 2010), and were subsequently refined through consultation by the Australian research team with a range of stakeholders from our community partners [Blinded for review]. The priority setting exercise will ask women to compare different pairings of the priorities, and to slide a marker to indicate which of the two is more important. An algorithm will then calculate their top priorities and provide tailored messaging to reflect their choices.

Women will then be asked to indicate whether they intend to stay in the relationship, leave the relationship, or whether they have already left. They will subsequently indicate their position on a modified version of the Contemplation Ladder (Biener \& Abrams, 1991), a tool originally developed to measure readiness to cease smoking. The ladder is designed to measure awareness of abuse from 0-10. If women's responses indicate that they are either unaware of the abuse, ambivalent about action, or intend to return to the abusive relationship, they will be directed to the motivational interviewing module.

The motivational interviewing module will encourage women to weigh up what they like or do not like about their relationship with their (ex) partner. It will ask them to input the positives and negatives about the relationship, as well as a specific action they could take that might make them feel better about their relationship or current situation. Some illustrative examples will be given, but women will be free to input whatever text they would like. The module will then ask women to indicate how motivated they feel to carry out their chosen action, and to identify what would need to happen in order for them to feel more motivated. It is anticipated that this exercise might allow women to assess the pros and cons of staying in the relationship, which may help increase self-efficacy (Benight \& Bandura, 2004; Hegarty et al., 2013a) and raise awareness if the negatives outweigh the positives. A recent randomised controlled trial conducted in the US suggested that motivational interviewing increased selfefficacy in the intervention group, however, their results were not statistically significant (Saftlas et al., 2014) and they recommended further investigation into this area. On completion of the motivational interviewing exercise, women will be directed to the action planning module.

The action planning module will use information provided by women throughout the I-DECIDE intervention to develop a tailored list of strategies. The individualised nature of the suggestions may make them more relevant and acceptable to women, and increase the likelihood of uptake. The action plan also acknowledges the multi-faceted nature of domestic violence, with the inclusion of strategies to help women deal with abuse that may be physical, emotional or financial. The list provided will also be responsive to level of safety and risk. If the woman has scored highly on the CAS (Hegarty et al., 2005) or the Danger Assessment (Campbell, 1986), she will be directed to an emergency safety plan with strategies such as locating a safe place to stay if the partner becomes abusive, taking copies of important documents, or using a code word to alert friends or family that she is in danger (McFarlane et al., 2004). For other women whose risk scores are lower, the tailoring will occur based on their responses to the priority module, and whether they wish to stay or leave the relationship. Some examples are shown in Table 2. A detailed description is provided when women click on a strategy, as well as resources that are localised to her particular State.

Table 2. Examples of tailored action planning strategies

\begin{tabular}{|l|l|l|}
\hline \multicolumn{1}{|c|}{ Priority } & \multicolumn{1}{|c|}{ Strategy } & \multicolumn{1}{c|}{ Example of Detail } \\
\hline Having resources & $\begin{array}{l}\text { Get further skills training or } \\
\text { education }\end{array}$ & $\begin{array}{l}\text { There are various ways to obtain further skills } \\
\text { training or education, although costs do vary. The } \\
\text { below sites can direct you to a Registered } \\
\text { Training Organisation (RTO) near you and outline } \\
\text { the courses currently on offer: [LINKS]. In some }\end{array}$ \\
\hline
\end{tabular}




\begin{tabular}{|l|l|l|}
\hline $\begin{array}{l}\text { My health and } \\
\text { wellbeing }\end{array}$ & $\begin{array}{l}\text { Talk with other women who } \\
\text { have survived abuse }\end{array}$ & $\begin{array}{l}\text { cases, courses can be completed entirely online... } \\
\text { women who have survived abuse. It can be } \\
\text { helpful to hear the stories of women who have } \\
\text { made positive changes in their lives, and learn } \\
\text { from their experiences. Sometimes it just helps to } \\
\text { know that someone understands what you are } \\
\text { going through... }\end{array}$ \\
\hline $\begin{array}{l}\text { My children's safety } \\
\text { and wellbeing }\end{array}$ & $\begin{array}{l}\text { Find somewhere to send your } \\
\text { children if your partner } \\
\text { becomes violent }\end{array}$ & $\begin{array}{l}\text { Violence between adults can be unsafe or } \\
\text { threatening for children. If they are old enough, it } \\
\text { may be better for children to leave the house if } \\
\text { your partner becomes abusive. Together with your } \\
\text { child, make a list of adults they feel safe with. } \\
\text { This could be a trusted neighbour, family member } \\
\text { or friend, but preferably somebody close by who } \\
\text { can be reached quickly... }\end{array}$ \\
\hline
\end{tabular}

The action planning process will potentially increase self-efficacy, as it will provide women with targeted, manageable options for actions they can take, and may reduce feelings of being overwhelmed and uncertain (Benight \& Bandura, 2004). It may also increase perceived support in two ways: first because the I-DECIDE website itself is playing a supportive role in "listening" to women, and because it facilitates the exploration of other possible sources of help within the community. These increases in perceived support may, in turn, foster self-efficacy even further (Benight \& Bandura, 2004). In line with the fluid nature of women's decision making, both the priorities module and the action planning can be revisited and changed by women at any time during the trial.

It is also possible that by perusing the full list of action plan strategies, which can be accessed after the individualised plan has been viewed, women may find useful resources and information that may enable them to combat any external factors limiting their movement on the change continuum.

Following on from the action planning, women will be directed to engage in a nondirective problem solving exercise. This exercise will encourage women to select one strategy they would like to enact. They will then be asked to input two possible solutions that are available for them to enact the strategy, and the advantages and disadvantages for each option. In theory, this will then lead to a clear preferred option being identified (MynorsWallis, Gath, Day, \& Baker, 2000) which women have chosen for themselves and can pursue when they are ready. Again, non-directive problem solving is likely to increase both selfefficacy and perceived support. Women may feel empowered by the fact that they have identified ways to overcome obstacles, and facilitate greater confidence in being able to face adversity and deal with any perceived barriers to change (Benight \& Bandura, 2004). They may also feel supported by I-DECIDE in leading them through this process. Both nondirective problem solving and motivational interviewing have been successfully transferred from face-to-face to web-based interventions for other problems such as lack of physical activity (Friederichs, Bolman, Oenema, Guyaux, \& Lechner, 2014), and diabetes management (Mulvaney et al., 2011), which suggests that there is potential for these interactive tools to work in the context of DV.

In summary, the I-DECIDE intervention could be an effective way for women experiencing domestic violence to self-reflect, self-assess and self-manage. The intervention is confidential and can be done anywhere, at any time. The time commitment from beginning to end is approximately 30 minutes, and the reading age score is estimated to be between 1213 years according to the Flesch-Kincaid readability test. Women may complete the 
intervention in multiple sittings, as they are able to log out and in again to pick up where they left off.

In early pilot work with women, the response to I-DECIDE was very positive. Some comments from women included:

I felt reassured, as though my feeling afraid or unsafe was taken seriously. I was glad to have what felt like an impartial and objective assessment of my situation.

I thought it really opened my eyes and confirmed the situation (made me more aware)

The relationship assessment was affirming, and made me feel 'backed up.' The action plans were relevant and useful

\section{Implications for Practice}

The theoretical journey described in this paper may assist other researchers developing interventions addressing DV, particularly in terms of how theory can be effectively harnessed and applied to develop an intervention. It may also be useful to those working to develop online interventions in other sensitive areas, as it explores the possibility of providing social support without face-to-face contact by using messaging developed in conjunction with the target user group. The I-DECIDE healthy relationship tool and safety decision aid may be a pathway to safety and healing for women experiencing DV, particularly for those who are unable to access formal services due to disability, location, or a controlling partner, however, it still needs to be rigorously tested in a randomised controlled trial. As with all interventions, there is a need for ongoing implementation research to embed the website into a real world situation (May et al., 2009).

\section{Conclusion}

This paper has outlined the theoretical and conceptual background to I-DECIDE, an online intervention for women experiencing DV. It has emphasised how the PRM can provide a useful framework for DV interventions through targeting awareness, self-efficacy and perceived support. Furthermore, the model's emphasis on the changeable and fluid nature of women's decision making and journey to change mirrors reality for many women (Feder, Hutson, Ramsay, \& Taket, 2006); this may make it easier for them to relate to an intervention where the target for change is not predetermined. These factors are important for I-DECIDE given that the tool is designed to be used without the need for the presence of a counsellor or other trained health professional. The paper has suggested ways in which I-DECIDE, as an online intervention, may be able to overcome some of the barriers encountered by face-toface DV interventions. It is hoped that the project will deliver a website that is acceptable, relevant, and widely-used by women experiencing DV, with the potential to reduce negative outcomes for this vulnerable population.

Funding: This work was funded by an Australian Research Council Discovery Project Grant, DP 130102799

\section{References}

Australian Bureau of Statistics. (2014). Household Use of Information Technology, Australia, 2012-2013, cat no. 8146.0. from http://www.abs.gov.au/ausstats/abs@.nsf/Latestproducts/8146.0Main\%20Features2201213 ?opendocument\&tabname $=$ Summary \&prodno=8146.0\&issue $=2012-13 \&$ num $=$ \&view $=$

Bair-Merritt, M., Lewis-O'Connor, A., Goel, S., Amato, P., Ismailji, T., Jelley, M., . . Cronholm, P. (2014). Primary Care-Based Intervetnions for intimate partner violence. Am J Prev Med, 46(2), 188-194. 
Bedi, G., \& Goddard, C. (2007). Intimate partner violence: what are the impacts on children? Australian Psychologist, 42(1), 66-77.

Benight, C. C., \& Bandura, A. (2004). Social cognitive theory of posttraumatic recovery: the role of selfefficacy. Behaviour Research \& Therapy, 42, 1129-1148.

Biener, L., \& Abrams, D. B. (1991). The Contemplation Ladder: Validation of a measure of readiness to consider smoking cessation. Health Psychology, 10(5), 360-365.

Campbell, J. C. (1986). Nursing Assessment for Risk of Homicide with Battered Women. Advances in Nursing Science, 8(4), 36-51.

Campbell, J. C., Webster, D., \& Koziol-McLain, J., et al. (2003). Risk factors for femicide in abusive relationships: results from a multisite case control study. Am J Public Health, 93(7), 1089-1097.

Chang, J. C., Dado, D., Hawker, L., Cluss, P. A., Buranosky, R., Slagel, L., . . Scholle, S. H. (2010). Understanding turning points in intimate partner violence: factors and circumstances leading women victims toward change. J Womens Health (Larchmt), 19(2), 251-259. doi: 10.1089/jwh.2009.1568

Christensen, H., Griffiths, K. M., \& Jorm, A. F. (2004). Delivering interventions for depression by using the internet: randomised controlled trial. BMJ. doi: 10.1136/bmj.37945.566632.EE

Cluss, P. A., Chang, J. C., Hawker, L., Scholle, S. H., Dado, D., Buranosky, R., \& Goldstrohm, S. (2006). The process of change for victims of intimate partner violence: support for a psychosocial readiness model. Women's Health Issues, 16(5), 262-274.

Council of Europe. (2011). Council of Europe Convention on preventing and combating violence against women and domestic violence (Vol. CETS no.210). Istanbul.

Dutton, M. (1992). Empowering and healing the battered woman. New York: Springer.

Eden, K. B., Dolan, J. G., Perrin, N. A., Kocaoglu, D., Anderson, N., Case, J., \& Guise, J. M. (2009). Patients were more consistent in randomized trial at prioritizing childbirth preferences using graphic-numeric than verbal formats. Journal of Clinical Epidemiology, 62(4), 415-424.

Ellsberg, M., \& Heise, L. (2005). Researching violence against women: a practical guide for researchers and activists. Washington D.C.: World Health Organization, PATH.

Ellsberg, M., Jansen, H. A., Heise, L., Watts, C. H., \& Garcia-Moreno, C. (2008). Intimate partner violence and women's physical and mental health in the WHO multi-country study on women's health and domestic violence: an observational study. The Lancet, 371(9619), 1165-1172.

Evans, M. A., \& Feder, G. (2015). Help-seeking amongst women survivors of domestic violence: a qualitative study of pathways towards formal and informal support. Health Expectations, Online. doi: doi: 10.1111/hex.12330

Feder, G., Hutson, M., Ramsay, J., \& Taket, A. (2006). Women exposed to intimate partner violence: expectations and experiences when they encounter health care professionals: a meta-analysis of qualitative studies. Archives of Internal Medicine, 166(1), 22-37.

Feder, G., Ramsay, J., Dunne, D., Rose, M., Arsene, C., Norman, R., . . Taket, A. (2009). How far does screening women for domestic (partner) violence in different health-care settings meet criteria for a screening programme? Systematic reviews of nine UK National Screening Committee criteria. Health Technology Assessment, 13(16), iii-iv, xi-xiii, 1-113, 137-347.

File, T., \& Ryan, C. (2014). Computer and Internet Use in the United States 2013: United States Department of Commerce: Census Bureau,.

Friederichs, S., Bolman, C., Oenema, A., Guyaux, J., \& Lechner, L. (2014). Motivational Interviewing in a Web-Based Physical Activity Intervention With an Avatar: Randomized Controlled Trial. Journal of Medical Internet Research, 16(2). doi: 10.2196/jmir.2974

Glass, N., Eden, K. B., Bloom, T., \& Perrin, N. (2010). Computerized aid improves safety decision process for survivors of intimate partner violence. J Interpers Violence.

Haggerty, L. A., \& Goodman, L. A. (2003). Stages of change-based nursing interventions for victims of interpersonal violence. Journal of Obstetric, Gynecological and Neonatal Nursing, 22, 68-75.

Hegarty, K., Bush, R., \& Sheehan, M. (2005). The Composite Abuse Scale: further development and assessment of reliability and validity of a multidimensional partner abuse measure in clinical settings. Violence Vict, 20(5), 529-547.

Hegarty, K., O'Doherty, L., Gunn, J., Pierce, D., \& Taft, A. (2008). A brief counseling intervention by health professionals utilising the 'readiness to change' concept for women experiencing intimate partner abuse: The weave project. J Fam Stud, 14(2-3), 376-388.

Hegarty, K., O'Doherty, L., Taft, A., Chondros, P., Brown, S., Valpied, J., . . G Gunn, J. (2013a). Effect of screening and brief counselling for abused women on quality of life, safety planning and mental health: A primary care cluster randomised controlled trial (weave). Lancet, 382(9888), 249-258.

Hegarty, K., O'Doherty, L., Taft, A., Chondros, P., Brown, S., Valpied, J., . . Gunn, J. (2013b). Screening and counselling in the primary care setting for women who have experienced intimate partner violence (WEAVE): a cluster randomised controlled trial. Lancet, 382(9888), 249-258. 
Hegarty, K., \& Taft, A. (2001). Overcoming the barriers to disclosure and inquiry of partner abuse for women attending general practice. Aust NZ J Public Health, 25(5), 433-437.

Hegarty, K., Tarzia, L., Murray, E., Valpied, J., Humphreys, C., A, T., . . G Glass, N. (Accepted 20/7/15). Protocol for a randomised controlled trial of a web-based healthy relationship tool and safety decision aid for women experiencing domestic violence (I-DECIDE). BMC Public Health.

Humphreys, C., \& Thiara, R. (2011). Readiness to change: mother-child relationship and domestic violence intervention. British Journal of Social Work, 41(1), 166-184.

Koziol-McLain, J., Vandal, A. C., Nada-Raja, S., Wilson, D., Glass, N., Eden, K. B., . . Case, J. (2015). A web-based intervention for abused women: the New Zealand isafe randomised controlled trial protocol. BMC Public Health, 15(56).

Lintvedt, O. K., Griffiths, K. M., Sørensen, K., Østvik, A. R., Wang, C. E. A., Eisemann, M., \& Waterloo, K. (2013). Evaluating the effectiveness and efficacy of unguided internet-based self-help intervention for the prevention of depression: a randomized controlled trial. Clinical Psychology and Psychotherapy, 20, 10-27.

Maciejewski, P. K., Prigerson, H. G., \& Mazure, C. M. (2000). Self-efficacy as a mediator between stressful life events and depressive symptoms. Differences based on history of prior depression. British Journal of Psychiatry, 176, 373-378.

May, C., Mair, F., Ballini, L., Dowrick, C., Eccles, M., Gask, L., . . . Rapley, T. (2009). Development of a theory of implementation and integration: Normalization Process Theory. Implementation Science, 4, 29.

McFarlane, J., Malecha, A., Gist, J., Watson, K., Batten, E., Hall, I., \& Smith, S. (2004). Increasing the safetypromoting behaviors of abused women. Am J Nurs, 104(3), 40-50.

Mulvaney, S. A., Rothman, R. L., Osborn, C. Y., Lybarger, C., Dietrich, M. S., \& Wallston, K. A. (2011). Selfmanagement problem solving for adolescents with type 1 diabetes: Intervention processes associated with an Internet program. Patient Educ Couns, 85(2), 140-142.

Murray, E., Burns, J., See Tai, S., Lai, R., \& Nazareth, I. (2005). Interactive Health Communication Applications for people with chronic disease. Cochrane Database of Systematic Reviews(4), CD004274. doi: 10.1002/14651858.CD004274.pub4

Mynors-Wallis, L. M., Gath, D. H., Day, A., \& Baker, F. (2000). Randomised controlled trial of problem solving treatment, antidepressant medication, and combined treatment for major depression in primary care. BMJ, 320(7226), 26-30.

O'Doherty, L., MacMillan, H., G, F., A, T., A.R., T., \& Hegarty, K. (2014). Selecting outcomes for intimate partner violence intervention trials: Overview and recommendations. Aggression and Violent Behavior, 19, 663-672.

O'Doherty, L., Taft, A., McNair, R., \& Hegarty, K. (In Press). Fractured Identity in the Context of Intimate Partner Violence: Barriers and Opportunities to Seeking Help in Health Settings. Violence Against Women.

Prochaska, J. O., \& DiClemente, C. C. (1982). Transtheoretical therapy: Toward a more integrative model of change. Psychotherapy: Theory, Research and Practice, 19, 276-288.

Ramsay, J., Carter, Y., Davidson, L., Dunne, D., Eldridge, S., Feder, G., . . . Warburton, A. (2009). Advocacy interventions to reduce or eliminate violence and promote the physical and psychosocial well-being of women who experience intimate partner abuse (Review). Cochrane Database of Systematic Reviews, Issue 3. Art. No.:CD005043. doi: 10.1002/14651858.CD005043.pub2

Ramsay, J., Feder, G., \& Rivas, C. (2006). Interventions to reduce violence and promote the physical and psychosocial well-being of women who experience partner abuse: a systematic review. . London: UK Department of Health.

Rees, S., Silove, D., Chey, T., Ivancic, L., Steel, Z., Creamer, M., . . Forbes, D. (2011). Lifetime prevalence of gender-based violence in women and the relationship with mental disorders and psychosocial function. JAMA, 306(5), 513-521.

Reisenhofer, S., \& Taft, A. (2013). Women's journey to safety - The Transtheoretical model in clinical practice when working with women experiencing Intimate Partner Violence: A scientific review and clinical guidance. Patient Educ Couns, 93(3), 536-548.

Richards, D., \& Richardson, T. (2012). Computer-based psychological treatments for depression: A systematic review and meta-analysis. Clinical Psychological Review, 32, 329-342.

Saftlas, A. F., Harland, K. K., Wallis, A. B., Cavanaugh, J., Dickey, P., \& Peek-Asa, C. (2014). Motivational interviewing and intimate partner violence: a randomized trial. Annals of Epidemiology, 24, 114-150.

Sawatzky, R. G., Ratner, P. A., Richardson, C. G., Washburn, C., Sudmant, W., \& Mirwaldt, P. (2012). Stress and Depression in Students: The Mediating Role of Stress Management Self-efficacy. Nursing Research, 61(1), 13-21. 
Taft, A., Hegarty, K., \& Flood, M. (2001). Are men and women equally violent to intimate partners? Aust NZ J Public Health, 25(6), 498-500.

Taft, A., O'Doherty, L., Hegarty, K., Ramsay, J., Davidson, L., \& Feder, G. (2013). Screening women for intimate partner violence in healthcare settings. Cochrane Database Syst Rev, Apr 30;4:CD007007. doi: 10.1002/14651858.CD007007.pub2.

Valpied, J., Cini, A., O'Doherty, L., Taket, A., \& Hegarty, K. (2014). 'Sometimes cathartic. Sometimes quite raw': Benefit and harm in an intimate partner violence trial. Aggression and Violent Behavior, 19, 673685.

Webb, T. L., Joseph, J., Yardley, L., \& Michie, S. (2010). Using the Internet to Promote Health Behavior Change: A Systematic Review and Meta-analysis of the Impact of Theoretical Basis, Use of Behavior Change Techniques, and Mode of Delivery on Efficacy. Journal of Medical Internet Research, 12(1: e4). doi: 0.2196/jmir.1376

World Health Organisation. (2013). Global and regional estimates of violence against women: prevalence and health effects of intimate partner violence and non-partner sexual violence. Geneva: WHO.

World Health Organization. (2013). Global and regional estimates of violence against women: prevalence and health effects of intimate partner violence and non-partner sexual violence. Geneva, Switzerland: World Health Organization.

Zickuhr, K., \& Smith, A. (2012) Digital differences. Washington D.C, USA: Pew Research Centre.

Zink, T., Elder, N., Jacobson, J., \& Klostermann, B. (2004). Medical management of intimate partner violence considering the stages of change: Precontemplation and contemplation. Annals of Family Medicine, 2(3), 231-239. 


\section{University Library}

\section{- M M N E R VA A gateway to Melbourne's research publications}

Minerva Access is the Institutional Repository of The University of Melbourne

Author/s:

Tarzia, L;Murray, E;Humphreys, C;Glass, N;Taft, A;Valpied, J;Hegarty, K

Title:

I-DECIDE: An Online Intervention Drawing on the Psychosocial Readiness Model for Women Experiencing Domestic Violence

Date:

2016-03-01

Citation:

Tarzia, L., Murray, E., Humphreys, C., Glass, N., Taft, A., Valpied, J. \& Hegarty, K. (2016). IDECIDE: An Online Intervention Drawing on the Psychosocial Readiness Model for Women Experiencing Domestic Violence. WOMENS HEALTH ISSUES, 26 (2), pp.208-216. https:// doi.org/10.1016/j.whi.2015.07.011.

Persistent Link:

http://hdl.handle.net/11343/57409 